\title{
Desequilibrio negocial y debilitamiento del actor sindical como efectos de la reforma laboral
}

\author{
Amaia OTAEGUI JÁUREGUI \\ Fundación $1^{\circ}$ de Mayo \\ aotaegui@ccoo.es
}

Recibido: 21-02-2013

Aceptado: 03-06-2014

\begin{abstract}
RESUMEN
El artículo propone un relato sobre los efectos y consecuencias de la reciente Reforma Laboral, su impacto en el sistema de negociación colectiva y sus implicaciones sociales. La hipótesis se resume en que para el caso español y en el contexto de la profunda e intensísima recesión económica, las medidas adoptadas han provocado una hecatombe y han terminado por agravar drásticamente la ya existente precariedad en las condiciones laborales que afecta a muchos sectores y amplios colectivos de trabajadores. A esta tendencia se añaden las intensas presiones que buscan consolidar una nueva correlación de fuerzas entre los interlocutores sociales, desde donde parece apuntarse una auténtica modificación de las 'reglas de juego' pues las sucesivas reformas laborales modifican a fondo las reglas de reconocimiento de los actores que han regulado los aspectos nucleares del modelo laboral.
\end{abstract}

Palabras clave: negociación colectiva, reforma laboral, desequilibrio, debilitamiento actores.

\section{Imbalance of collective bargaining and weakening of social actors as a result of the labour reform}

\begin{abstract}
This article offers an account of the effects and consequences of the recent Labour Reform, its impact on the collective bargaining system and its social implications. The hypothesis is based in the context of deep and intense economic crisis, where the adopted measures have caused a catastrophe and have come to dramatically worsen the existing precarious working conditions affecting many sectors and large groups of workers. To these trend is added the intense pressures to consolidate a new balance of power between the social partners, and also stands a real modification of the social actors because the labour relations rules are changed
\end{abstract}

Keywords: collective bargaining, weakening, unions, labour.

REFERENCIA NORMALIZADA: Otaegui Jáuregui, A. (2014) "Desequilibrio negocial y debilitamiento del poder del actor sindical como efectos de la Reforma Laboral". Cuadernos de Relaciones Laborales, Vol. 32, núm. 2, p. 337-360.

SUMARIO: Introducción. 1. La especial incidencia de la crisis global. 2. El vendaval de reformas laborales. 3. Innovaciones de la reforma laboral de 2012. 4. Efecto 1: 'vacíos' de negociación y disminución de su 
cobertura. 5. Efecto 2: Reducción salarial y empobrecimiento de los trabajadores. 6. Efecto 3: Declive de la 'gobernanza' interna. 7. Valoración final. 8. Bibliografía.

\section{Introducción}

En el ámbito del mercado de trabajo y del intercambio laboral, el sistema de negociación colectiva es una institución fundamental cuya práctica ha configurado una realidad compleja y diversa, atravesada por variadas y a menudo conflictivas relaciones. Aunque el Estado ha jugado siempre un papel preponderante a la hora de determinar las reglas concretas de los procedimientos negociales, se advierte que no existe un sistema único de relaciones colectivas sino que, incluso desde el propio ordenamiento jurídico, se ha promocionado un sistema o modelo de negociación con niveles diversificados, con temas y contenidos diversos, en el que las decisiones y las prácticas desarrolladas por los propios sujetos negociadores han tenido una gran influencia en el grado de articulación o la autonomía de los propios niveles de negociación.

Dicha diversidad aparece como una característica derivada del cruce dinámico de una pluralidad de variables históricas, económicas, jurídicas e institucionales, a las que se añaden los procesos conflictivos y en ocasiones plagados de tensiones entre las propias fuerzas productivas, y cuyo acoplamiento funcional a las estructuras sociales, lógicamente, no es siempre exacto. La explicación de la negociación colectiva como producto de las acciones, estrategias y tácticas de los actores concretos (Alonso, L. E. 2011) se deriva de la centralidad de su dimensión como elemento de intercambio político y, en especial, por su demostrada capacidad de atravesar y ocupar el espacio público, de trascender el marco del ámbito laboral y de adquirir un relieve y un impacto que afecta a 'toda la comunidad' (Pérez de Guzmán, S. 2012). De este modo se entiende la extraordinaria importancia de las circunstancias sociopolíticas concretas en la evolución de las estrategias de los actores presentes en las relaciones laborales.

Este modelo polifuncional que en sus aspectos estructurales no había cambiado en los últimos veinte años, está siendo sometido a fuertes tensiones como consecuencia de la marea de políticas de austeridad y recortes que se implementan por toda Europa, haciendo que sus pilares básicos se tambaleen. Pero las políticas que se plantean para salir de la crisis tienen muy distintos efectos dependiendo del tipo de estructura productiva, la tasa de empleo, el nivel de productividad, la relación entre flexibilidad y seguridad en las relaciones laborales o el papel atribuido a los actores sociales (Clauwaert and Schömann, 2012).

El artículo propone un relato sobre los efectos y consecuencias de las recientes reformas laborales que impactan en nuestro sistema de negociación colectiva y sus implicaciones en la sociedad. Si bien encontrar evidencias empíricas e información estadística que corrobore esta hipótesis no es una tarea sencilla, en razón del escaso tiempo transcurrido pero también debido al riesgo de establecer predicciones o pronósticos en tan corto plazo, la intensidad y el rango de las diversas medidas e 
iniciativas dirigidas al ámbito laboral, aún siendo muy recientes en el tiempo, son de tal envergadura, al menos desde la perspectiva de las relaciones laborales como pieza clave del desarrollo económico y, por tanto, de la dinámica y evolución de las relaciones sociales, que merecen un tratamiento y atención especiales.

La hipótesis de este artículo se resume en que para el caso español (aunque no solo), y en el contexto de la profunda e intensísima recesión económica, las medidas adoptadas en vistas a promocionar una mayor capacidad de adaptación de las empresas a las circunstancias de los mercados, han provocado una hecatombe y ha terminado por agravar drásticamente la ya existente precariedad en las condiciones laborales que afecta a muchos sectores y amplios colectivos de trabajadores. El modelo que sostiene estas medidas sustenta la competitividad en mecanismos de devaluación interna -básicamente devaluación salarial y abaratamiento del coste del trabajo- y desregulación del sistema de negociación colectiva, intensificando las tendencias a largo plazo hacia la polarización salarial y la segmentación del mercado de trabajo (Rojo, E. 2013).

A pesar de su extensión y profundidad, todo parecería indicar que, siendo ésta una tendencia central de transformación, no sería en absoluto la única, puesto que a esta tendencia se añaden las intensas presiones que buscan consolidar una nueva correlación de fuerzas entre los interlocutores sociales. A este respecto, parece apuntarse la perspectiva de asistir a una auténtica modificación de las 'reglas de juego' (Sanguinetti, W. 2012), pues las sucesivas reformas laborales modifican a fondo las reglas de reconocimiento de los actores que han regulado los aspectos nucleares del modelo laboral. En concreto, se pone en práctica la desconsideración de la negociación colectiva como institución dependiente de los agentes que la componen, de las reglas que delimitan las formas de relación e interdependencia y del establecimiento de pautas de conducta que posibilitan su reconocimiento mutuo. Esta desregulación se acompaña del debilitamiento del diálogo democrático que había caracterizado el llamado 'modelo social europeo', herramienta que descansaba sobre el consenso de reconocer la importancia de los agentes de la negociación, como representantes de intereses conflictivos pero negociables (Clauwaert and Schomann, 2011).

Este artículo está lejos de ser exhaustivo y reconoce de partida la limitación de ceñirse a una visión panorámica y genérica del conjunto de los posibles efectos sociales y laborales de estas políticas respecto a la estructura, la dinámica e incluso el contenido de la negociación colectiva, pero deja de lado otros elementos o dimensiones que desde la acción política contribuyen a la progresiva aparición de altos niveles de desigualdad, desarticulación y descohesión social. Desde este reconocimiento, no quisiera sin embargo, renunciar a ofrecer una primera aproximación, en cierto modo transversal, a cerca de la visión, la respuesta $\mathrm{y}$, en definitiva, la acción de los interlocutores sociales y su perspectiva estratégica en este contexto. 


\section{La especial incidencia de la Crisis global}

Los sistemas laborales europeos están sufriendo cambios y transformaciones de gran calado como resultado de las instrucciones de las autoridades monetarias ante la crisis global, pudiendo llegar a causar una 'revolución profunda y duradera' en los elementos estructurales y en la propia sustancia de la negociación colectiva y las prácticas laborales (Comisión Europea, 2012). Aunque en el diagnóstico que de esta crisis realizan la Comisión Europea, el Banco Central Europeo o el Fondo Monetario Internacional, se comienza por reconocer de buena gana que el origen de la crisis es el desorden financiero que ha afectado a todos los países, las medidas que se prevén para superarla no son de la misma naturaleza. De hecho, las autoridades más altas de la Unión Europea ejercen una fuerte presión sobre los Estados Miembros en aras de facilitar el funcionamiento y la recuperación del dinero prestado de los bancos europeos y los mercados, para lo cual requieren que los Estados tengan menos capacidad de intervención real. En la práctica, el sistema de la llamada 'gobernanza' económica implica que tanto desde la Comisión como desde el Consejo Europeo se asumen amplios poderes que les permiten imponer en algunos países reformas laborales que denominan 'voluntarias'.

Una de las claves que vertebra esta línea de actuación política (que aunque es externa, se encuentra absolutamente en buena sintonía con las orientaciones de los gobiernos nacionales (Rodríguez, 2013) extiende y consolida el mensaje de que la 'única' posible salida de la crisis requiere de la afectación directa sobre algunas características del ámbito sociolaboral y el mercado de trabajo (Baumann 2005, Sennet 2000), y su resolución depende en buena manera de la disposición de los actores laborales a flexibilizarse y a modernizar la 'compleja y anticuada' legislación laboral. Tras el Pacto del Euro Plus en 2011, el 'Six Pack' y el Pacto Fiscal, se evidencia con claridad la pretensión de que las reformas laborales procuren que las disposiciones se flexibilicen y se relaje el marco normativo, y siguiendo esta lógica, las 'agendas' políticas de algunos países están claramente orientadas por la implementación intensa y acelerada de un 'pack' de instrumentos y herramientas considerados claves para la superación de la crisis, presididos por la búsqueda de desregulación de los sistemas de negociación colectiva y del abandono de los marcos de diálogo social tradicionales en el 'modelo social europeo' (Clauwaert y Schömann, 2012).

De hecho, las palabras de la propia Comisión Europea ${ }^{2}$ transmiten como mensaje que para reducir las altas tasas de desempleo, consideran como objetivo positivo 'facilitar las modalidades de contratación flexible en las empresas, reducir las indemnizaciones por despido y simplificar los procedimientos de despido

${ }^{1}$ Los casos de Grecia y Portugal no podrían ser calificados en modo alguno como de reformas 'voluntarias'.

${ }^{2}$ Comisión europea 2010 http:// ec.europa.eu/economy_finance/articles 
individual y colectivo'. También se muestran favorables a implementar medidas que procuran la flexibilización de los salarios y confirman que 'se han suavizado las condiciones que permiten a las empresas no aplicar los acuerdos de negociación colectiva de nivel superior y se han revisado los convenios salariales sectoriales', para lo cual reclaman el máximo compromiso posible de los ciudadanos. Como apunta el informe de la propia Comisión Europea, son las propias estructuras de diálogo social a escala europea y la función de los interlocutores sociales las que se encuentran en entredicho ${ }^{3}$.

Los mecanismos de ajuste en los mercados de trabajo para la recuperación de la competitividad adquieren materialidad y concreción en torno a medidas que tratan de aumentar el margen de maniobra de las empresas (flexibilidad interna y externa), y para llevar a cabo esta operación resulta inevitable la modificación de las legislaciones laborales nacionales. Los discursos que desde un supuesto 'modelo racional' presentan las reformas como herramientas que quieren atajar el trabajo precario y la segmentación laboral, tan presentes en nuestro mercado de trabajo, junto a una contundente calificación de 'rigidez' del ámbito normativo, convierten, de facto, la cualidad de la eficiencia económica en el único criterio o condición bajo la que se someten a evaluación los sistemas de negociación colectiva. De forma paralela, el mensaje de que la recuperación de la competitividad de las economías nacionales en un entorno globalizado requiere del desmantelamiento de dichos sistemas laborales se va convirtiendo en una obsesión abusiva y repetitiva (Alonso, L. E., 2013).

Resulta innegable que esta presión hacia los sistemas de negociación colectiva para que se descentralicen y abandonen o, al menos relajen, el ámbito territorial y sectorial de negociación, priorizando el ámbito de la empresa ${ }^{4}$, deriva básicamente del objetivo central de incentivar que la fijación de los sistemas salariales abandonen las referencias a la inflación anual y se referencien en criterios basados en la productividad ${ }^{5}$. En efecto, la desaparición del tipo de cambio y la

${ }^{3}$ Comisión Europea (2013) 'Relaciones industriales en Europa'.

4 Informe OCDE (2012): Una opción para mejorar la flexibilidad necesaria para adaptarse a las condiciones económicas es abolir la extensión legal de los acuerdos de negociación colectiva de nivel superior o reemplazarla por un régimen de consentimiento previo, donde los empleadores decidan si desean ser representados en la negociación salarial sectorial.

5 Se trata de una respuesta a las demandas del Consejo Europeo cuyo objetivo fundamental es fortalecer la coordinación de la política económica en favor de la "competitividad y la convergencia". El Pacto dice expresamente que "respetando las tradiciones nacionales de diálogo social y relaciones laborales", los países deberían tomar medidas "que garanticen la evolución de los costes de acuerdo con la productividad", revisando los acuerdos de fijación salarial y descentralizando el proceso de negociación colectiva y de los mecanismos de indexación; y además, fomentar la "flexiseguridad". 
convergencia de los precios en torno a una tasa de inflación baja, orientan a los Estados a implementar políticas para conseguir la desinflación salarial. Es precisamente este mecanismo de espiral descendente en los salarios nominales y reales el que trata de reemplazar la devaluación monetaria, que ha sido el instrumento tradicionalmente utilizado para mantener un cierto tipo de competitividad entre un cierto tipo de países la Unión Europea (Confederación Europea de Sindicatos, 2012).

Ahora bien, desde la perspectiva europea, y a pesar de que esta relación de medidas e intervenciones para el ajuste económico y financiero tienen una naturaleza común en la mayoría de gobiernos, instituciones y países, la evaluación de su puesta en práctica muestra sin duda una gran diversidad y muy distinto alcance, sucediendo que tanto la magnitud de sus efectos como la dimensión de sus consecuencias, son indudablemente plurales y muy heterogéneos ${ }^{6}$. De hecho, en los países caracterizados por instituciones sociolaborales más sólidas -entendidas como las presididas por un cierto equilibrio de poderes y contrapoderes entre empresarios y sindicatos- ${ }^{7}$, y un mayor desarrollo del 'modelo social', parece que la intensidad de las reestructuraciones ha sido en ocasiones matizada, y los procesos de desregulación de las instituciones laborales han tenido un carácter más puntual, de forma que la profundidad de sus efectos estarían directamente vinculados con la coyuntura de las circunstancias económicas, al tiempo que la intensidad de los conflictos podrían calificarse como de limitado alcance (Comisión Europea, 2012). En otros países miembros, (entre los cuales la actuación del gobierno español en el seguimiento y aplicación de las recomendaciones de la nueva 'gobernanza' económica ha sido ejemplar), se ha acentuado la reducción o eliminación de los desequilibrios aplicando con intensidad y rigor los rígidos requerimientos de consolidación fiscal y estabilidad financiera.

En suma, crisis económica y altísimas tasas de desempleo se emplean para justificar la profunda desregulación del modelo general de relaciones laborales, en la que ambos fenómenos se acompañan y suceden en una frenética espiral temporal. Este proceso se lleva a cabo con tal rapidez y celeridad que, en su exaltación, incluso peca de falta de respeto a los procedimientos y fundamentos democráticos, negando la participación e intervención a los actores colectivos y representantes sociales, lo que a la postre significa la ruptura de la línea de equilibrio presente en

\footnotetext{
${ }^{6}$ Un análisis de los heterogéneos efectos sociales de la crisis se encuentra en Laparra, M y Pérez Eransus (2012): 'Crisis y fractura social en Europa'. Obra Social 'La Caixa'.

${ }^{7}$ Schnabel et alt. (2006) y Frege y Kelly (2003) sostienen que un marco institucional es fuerte cuando presenta tres características: la primera es que los derechos y las obligaciones de las partes cuando negocian se encuentran formalmente establecidos; la segunda, se refiere a que los empleadores y los trabajadores están organizados y el Estado determina por ley quiénes son los actores que están reconocidos para firmar acuerdos y convenios. Finalmente, los acuerdos firmados son de carácter obligatorio para las partes.
} 
las tres décadas anteriores representado por el sistema keynesiano de regulación social.

La fórmula que se alumbra para la implementación de esta estricta austeridad económica y presupuestaria no tiene en cuenta que su aplicación o implementación no se implementa en el vacío sino que, muy al contrario, se propaga alrededor de un contexto previo donde la desindustrialización, la fragmentación laboral, el desempleo y la fuerte precarización preexistentes son el caldo donde se cultiva el debilitamiento del Estado del bienestar y el agotamiento de sus políticas sociales, de sus políticas de mercado de trabajo y de sus instituciones (Pérez, L. y Viñas, A.I. 2012). Procesos de intensa restructuración y desregulación que visibilizan la búsqueda de una devaluación interna del sistema sociolaboral (por agotamiento) y la adaptación pasiva $\mathrm{o}$, incluso, la desintegración de los agentes que intervienen en el sistema productivo (por su presunta ineficacia). Procesos que -no olvidemos-, al mismo tiempo contribuyen, y de ahí su radical importancia, a definir y diseñar un modelo futuro de relaciones laborales presidido por la exaltación de la competitividad y la competencia, con total ausencia de referencias colectivas y sociales.

\section{El vendaval de reformas laborales}

Los primeros efectos de la crisis económica en 2008, con la enorme destrucción de empleo como gran protagonista del mercado de trabajo y de la escena pública, abren las puertas a un fortísimo y convulso vendaval en el ámbito económico, social y político. A partir de la caída en picado del ciclo económico, el brutal colapso de la economía genera el crecimiento desbocado de las tasas de desempleo, y el modelo de diálogo social, que había constituido una 'seña de identidad' del ámbito de las relaciones laborales, se paraliza y rápidamente endurece las posiciones de los agentes sociales. La patronal, invocando el restablecimiento de la rentabilidad y la competitividad de las empresas, vuelve a poner en la agenda su reivindicación tradicional de flexibilización del mercado de trabajo, a través de la reducción del coste del despido para los trabajadores estables, al tiempo que exige 'sacrificios' salariales. Las organizaciones sindicales, por su parte, argumentan la existencia de múltiples indicios que confirman la incidencia relativa del sistema laboral sobre el mercado de trabajo, y la dependencia de éste en relación a otras variables distintas, básicamente la actividad económica y el modelo productivo ${ }^{8}$, al tiempo que tratan de mantener el poder adquisitivo de los salarios como la herramienta más directa para el sostenimiento de la demanda.

\footnotetext{
${ }^{8}$ Entre estos claros indicios se encuentra que el crecimiento de la tasa de empleo en los años previos se produce con la misma regulación laboral a la que ahora se culpa de 'rigidez'.
} 
En el plano del diálogo social, a pesar de las expresiones declarativas de apoyo en torno a la validez del procedimiento por parte de todos los actores sociales, éste se paraliza pues la patronal solo tiene que esperar la próxima y cercana evolución de la coyuntura política hacia posiciones más favorables a sus intereses. En esos momentos, la negociación colectiva experimenta un considerable parón, debido a la estrategia de bloqueo de la negociación a nivel sectorial y de empresa, en la práctica totalidad de los casos, de las organizaciones patronales. Como ya se reflejaba en el 'Informe de Seguimiento de convenios con datos compartidos entre UGT, CCOO, CEOE y CEPYME' de agosto de 2013, los datos sobre el bloqueo de la negociación eran ya claros y evidentes en 2010 , se acrecentaron en 2011 y $2012^{9}$ y se han extendido durante 2013.

Las respuestas desde el ámbito político no se hacen esperar, y las reformas laborales de 2010 y 2011, realizadas por el entonces gobierno socialista, ponen en marcha una serie de medidas que se califican como 'inevitables', y que se aprueban después del fracaso por falta de acuerdo entre los agentes sociales. En el objetivo expresamente declarado de que pudieran servir como freno ante el imparable e intensísimo proceso de destrucción de empleo, se ponen en marcha mecanismos para la implementación y promoción de diversas medidas de flexibilidad interna en las empresas para su (mejor) adaptación a las especiales coyunturas económicas. Ambas reformas afirman que sus objetivos prioritarios son 'potenciar los instrumentos de flexibilidad interna en el transcursos de las relaciones laborales, favoreciendo la adaptabilidad de las condiciones de trabajo a las circunstancias de la producción bajo la consideración general de que dichos instrumentos constituyen una alternativa positiva frente a medidas de flexibilidad externa que implican un ajuste en el volumen de empleo ${ }^{, 10}$.

De forma específica, la reforma en materia de negociación colectiva de 2011 mostraba una decidida orientación hacia el fortalecimiento de la negociación a nivel de empresa frente al nivel sectorial, y al mismo tiempo articulaba intentos serios de introducir elementos de agilidad y rapidez en los procedimientos y también en los mecanismos de solución de las discrepancias entre las partes intervinientes en la negociación (Fernández, M.F. 2012). La voluntad de cambio se subrayaba en la posibilidad de que el convenio colectivo de empresa pudiera inaplicar condiciones salariales pactadas en un colectivo superior ${ }^{11}$, así como en permitir la modificación de condiciones de trabajo derivadas de la negociación colectiva. Desde la

9 Un análisis detallado sobre este aspecto se encuentra en: http: //www.ccoo.es/comunes/recursos/1/ doc164979.

${ }^{10}$ Exposición de motivos Ley 35/2010 de medidas urgentes para la reforma del mercado de trabajo y Real Decreto- Ley 7/2011 de medidas urgentes para la reforma de la negociación colectiva.

${ }^{11}$ El 'descuelgue salarial' no era una institución realmente nueva, sino derivada de la Reforma Laboral de 1994, pero la fórmula se contempla de manera más detallada. 
perspectiva de la estructura, los criterios para la descentralización de la negociación colectiva incluían la posibilidad de que los agentes sociales, organizaciones sindicales y empresariales más representativas, definieran los criterios de la estructura sectorial, manteniendo intacta a través de la fórmula "salvo pacto en contrario' los elementos claves de la autonomía colectiva y la capacidad de que los negociadores ordenaran y articularan el conjunto de la estructura del sector. Se trataba sin duda de una fórmula que tratada de articular los requerimientos de la realidad socioeconómica con la voluntad de los interlocutores sociales como lugar típico para el desenvolvimiento de la representatividad de las partes, y en la órbita de ordenamientos similares en otros países, se mantenía la lógica de la búsqueda de consensos y el estímulo para las soluciones negociadas, la transparencia y una cierta estabilidad en su vigencia.

Por su parte, los agentes sociales centraron su apuesta estratégica en la búsqueda de reapertura de un nuevo marco interconfederal para el empleo y la negociación colectiva (ANC), a través del cual retomaron el diálogo social bipartito y trataron de desbloquear la negociación colectiva a nivel sectorial. En este acuerdo, los agentes sociales pretendían mantener un escenario regulador de negociaciones formales, confirmando su apuesta principal por la flexibilidad interna 'pactada' y la descentralización controlada del sistema de negociación. El 'Acuerdo social y Económico de 2011' y el 'II Acuerdo para el Empleo y la Negociación colectiva para los años 2012-14', a modo de guía para el conjunto de la negociación, establecían una serie de referencias salariales, así como criterios para avanzar en la estructura y los contenidos de la negociación colectiva, tratando de aunar la posibilidad de flexibilizar algunas materias en los convenios con el mantenimiento del principio general de equilibrio entre las partes, donde la capacidad decisoria del empleador fuera acompañada de una competencia similar en el lado de la representación colectiva de los trabajadores.

Se trataba de un verdadero esfuerzo de los agentes sociales por defender una estructura reguladora que mantuviera el control sobre la 'flexibilidad negociada'. Su manifestación más específica en el ámbito de la estructura de la negociación incluye, entre las recomendaciones y criterios que se dirigen a los negociadores, que los convenios sectoriales propicien que la empresa sea el ámbito de negociación en materias como salarios y jornada e incluye además, una serie de recomendaciones en el objetivo de lograr una fuerte moderación salarial: hasta el $0,5 \%$ en 2012 , hasta el $0,6 \%$ en 2013 , y una banda que oscila entre el $0,6 \%$ o el $1,5 \%$, en función del crecimiento de la economía para 2014. Del texto del Acuerdo se desprende que los incrementos superiores a esos porcentajes deberían sustentarse en crecimientos de la productividad ${ }^{12}$. Semanas después de la firma de este acuerdo, los agentes sociales suscribieron el V Acuerdo sobre Solución Autónoma de Conflictos Laborales, dedicado en gran medida a tratar de evitar bloqueos en la negociación

12 II Acuerdo para la negociación colectiva y para el empleo 2012-2014. 
colectiva ante la existencia de desacuerdos, regulando los procedimientos aplicables en los supuestos de fracaso de la misma o de los periodos de consulta en materia de inaplicación del convenio o despidos colectivos ${ }^{13}$.

Como primera consecuencia de este esfuerzo en aras de la moderación salarial, el crecimiento salarial pactado incluso después de aplicarse las cláusulas de revisión salarial, reflejó una pérdida de poder adquisitivo de los salarios, en una mayor cuantía el segundo año que el primero, a la que habría que añadir la congelación que supuso la no renovación de las condiciones salariales de un número importante de empresas y trabajadores. Pero es suficientemente conocido que este intento por parte de los agentes sociales para avanzar en la vía de la autonomía colectiva y la autorregulación, fracasó, pues fue insuficientemente valorado y claramente despreciado por el gobierno (Escudero, 2013).

\section{Innovaciones de la reforma laboral de 2012}

Solamente tres meses después de su llegada al poder, el Gobierno presidido por Rajoy puso en marcha una reforma laboral que venía precedida por el anuncio de que su intención era representar un radical cambio de modelo en la forma de concebir las relaciones laborales, el espacio del diálogo social y la negociación colectiva. Y en efecto, supone un radical cambio de modelo pues su alcance es muy amplio, reduciendo sus márgenes e impactando sobre su estructura y su contenido. La reforma expresa de manera diversa su voluntad de transformar el panorama negocial previo a través de varios mecanismos: la mayor facilidad para la inaplicación transitoria de los convenios colectivos, sectoriales o de empresa; la prioridad aplicativa expansiva y desvertebradora del convenio colectivo de empresa sobre el sectorial; el debilitamiento de la capacidad de intervención sindical en los cambios organizativos, ajustes de plantilla o reestructuraciones de empresa; la eliminación de la intervención administrativa; y la pretensión de limitar el alcance del control judicial por medio de una definición amplísima de las causas que condicionan determinadas decisiones empresariales.

Presidida por la voluntad de robustecer los poderes empresariales y debilitar consiguientemente la posición ocupada por los trabajadores (Escudero, 2012), la negociación colectiva es sometida a un proceso de desvitalización de algunos de sus 'nervios' esenciales a través de dos líneas: por un parte, siguiendo el argumento de facilitar la adaptación de una empresa a una situación productiva o económica específica, el convenio sectorial ha sido 'intervenido' por la norma legal en el sentido de reorientar su funciones y su centro de gravedad hacia la empresa, hasta el punto de dotar de prioridad aplicativa absoluta a este nivel de negociación. Esta es precisamente la seña de identidad específica de esta reforma, que el convenio de

${ }^{13} \mathrm{~V}$ Acuerdo para la solución autónoma de conflictos laborales. 2012. 
empresa pueda negociarse sin ningún tipo de vinculación con la negociación colectiva sectorial, a través del mecanismo de hacer desaparecer el principio general de no concurrencia entre convenios, cuyo resumido significado es que un convenio no podía afectar en lo regulado por otro.

En términos de equilibrio de las relaciones de trabajo, los efectos son demoledores, pues el empresario aumenta su capacidad de modificar las condiciones de trabajo desde el recurso a 'causas económicas, técnicas, organizativas, o de producción', devaluando o degradando la exigencia de motivación causal para considerarse justificada en la modificación de condiciones de trabajo (Molero, 2013) ${ }^{14}$. También se simplifican los trámites para que el empresario pueda 'descolgarse' o inaplicar las condiciones de trabajo reguladas en el convenio de aplicación, que además del salario ${ }^{15}$ alcanza ahora a otras condiciones de trabajo, como jornada (horario y distribución), clasificación profesional y adaptación de las modalidades de contratación. Se abre de este modo la posibilidad de inaplicar o hacer decaer la regulación de condiciones de trabajo y empleo llevada a cabo por el convenio sectorial, con un procedimiento bastante sencillo.

Pues bien, esta intervención legal en el modelo de negociación, destinada a dar un protagonismo absoluto a la negociación de empresa, puede ser descrita como 'descentralización sin coordinación', o 'evolución descontrolada' y descoordinada de funciones desde los niveles altos a los bajos, en la medida que cuestiona seriamente las posibles dimensiones del convenio sectorial, desconsidera que la negociación sectorial tenga alguna aportación o papel específico como instrumento de racionalización de la competencia entre las empresas, o como un pacto implícito de no concurrencia entre ellas por la vía del 'dumping' de costes laborales (González de Lena, 2012). De hecho, no solo el convenio sectorial general o estatal podría quedar desprotegido frente a la posible regulación a la baja en las condiciones de trabajo que pueda hacer cualquier convenio de empresa, sino que esa posibilidad afecta a cualquier convenio colectivo sectorial autonómico, provincial, o acuerdo interprofesional (Merino, A. 2012). De forma que, como primera consecuencia, resulta perfectamente factible que las pequeñas y medianas empresas queden fuera del amparo o 'paraguas' del convenio sectorial, bien por la posible negociación de un convenio de empresa propio, bien porque se han potenciado y facilitado las llamadas 'cláusulas de inaplicación' del convenio aplicable de ámbito superior (introduciendo un arbitraje obligatorio en caso de desavenencias entre las partes). En esta dirección, la prevalencia del modelo de minifundismo empresarial (cuya traducción se refleja en que más del 75 por ciento

${ }^{14}$ Un análisis particularizado se encuentra en Molero M. L: 'El nuevo modelo de flexibilidad interna' en Escudero, R. (coord.). La negociación colectiva en las reformas laborales de 2010, 2011 y 2012. Ed. Cinca.

${ }^{15} \mathrm{El}$ 'descuelgue salarial' era posible desde la Reforma laboral de 1994 
de las empresas tiene menos de 6 trabajadores y más del 85 por ciento tiene menos de 10), condiciona la calidad de la negociación colectiva que se desarrolla en ellas, donde, en el mejor de los casos, lo hace en términos de fuerte desequilibrio de poder (Rodríguez, L. 2012).

La otra gran línea de desvitalización del modelo negocial se procura a través de la intensa limitación de la ultra-actividad de los convenios, cuyo significado es que los convenios que no sean renovados decaerán al año de su finalización. Así, al encarar su renovación, se abre un escenario de nuevos e importantes desequilibrios de poder entre las partes, afectando tanto a los convenios sectoriales como a los de empresa. La eliminación de la ultra-actividad abre la puerta a diversas situaciones, incluyendo la posibilidad de que si la parte empresarial no renueva los convenios colectivos sectoriales, se podría aplicar con carácter general, -por ejemplo en el aspecto de la regulación salarial- incluso el salario mínimo interprofesional, cuya reducida cuantía en comparación con la media europea es bien conocida ${ }^{16}$. En contra de su enfática proclamación como paradigma de equilibrio, coherencia y modernización (Escudero 2013), esta profunda quiebra del modelo de negociación comienza ya a mostrar varios efectos en las relaciones laborales.

\section{Efecto 1: 'Vacíos' de negociación y disminución de su cobertura}

Una medida de la intensa actividad convencional existente en los años anteriores al inicio de la crisis se refleja en los datos proporcionados por el Balance de la Estadística de Convenios publicada por el Ministerio de Empleo, donde se refleja que en el año 2007 existían más de 6000 convenios colectivos. A partir de esa fecha, que es el punto álgido de la Estadística, el número de convenios comienza a decaer, y esta tendencia se intensifica y profundiza de forma más acusada debido a la finalización y/o no renovación de muchos de ellos durante 2010, 2011 y 2012. De hecho, el rasgo más sobresaliente en esos años es la ralentización de la negociación y los datos proporcionados por esta fuente estadística señalan sin lugar a dudas una potentísima tendencia de decaimiento. Esta tendencia se refleja en los datos correspondientes al año 2012, todavía provisionales, donde la caída de los convenios con respecto a 2007 se observa con total claridad. En ellos se pone de manifiesto que la reducción del número de convenios es muy llamativa, disminuyendo desde los más de seis mil convenios existentes en 2007 a casi 3.900 en solo cinco años. Al mismo tiempo, los convenios sectoriales se han reducido de forma considerable. La información disponible del año 2013 debe tomarse con muchísima cautela debido al considerable retraso en el registro de los convenios correspondientes a ese año, que por tanto son muy inestables. A pesar de ello, los primeros datos disponibles confirman y agravan este cambio de tendencia, que se

${ }^{16} \mathrm{Su}$ evolución comparada se puede observar en: http://www.salariominimo.es/. 
observa no solamente con respecto a 2007, sino con arreglo a 2012, puesto que hasta diciembre de 2013 se habían registrado algo más de 2.150 convenios, que afectan a algo más de seis millones y medio de trabajadores ${ }^{17}$. Aunque el cómputo final correspondiente a 2013 (e incluso el de 2012, todavía sin finalizar) proporcione un mayor número de convenios para ese año, pues el goteo en el registro de convenios es incesante, se pone en evidencia que se registran casi 1.500 convenios menos (casi un $43 \%$ menos) que el año anterior.

Desde las particulares características de nuestra estructura productiva, como su profunda heterogeneidad y su clásico minifundismo, lo que resulta relevante de esta disminución del número de convenios es que, en paralelo, disminuye la cobertura negocial, y lo hace de forma nítida: de los más de once millones y medio de trabajadores cubiertos por algún convenio fruto de la negociación colectiva en 2007, esta cifra ha bajado hasta nueve millones cuatrocientos mil en el año 2012, es decir, una disminución de más de dos millones de trabajadores en cuatro años. Lo más preocupante de las expectativas hacia el futuro es la ausencia de mejora, pues los datos provisionales del Ministerio de Empleo correspondientes a $2013^{18}$ indican que los trabajadores cubiertos por convenio alcanzaban a algo más de seis millones y medio de asalariados, dato que no parece achacable únicamente a la alta tasa de desempleo existente (un $30 \%$ menos). La información en relación a la cobertura resulta sin duda más relevante que su número, y dada la importancia del convenio de empresa proporcionada por la reforma laboral, se podría aventurar que en un futuro próximo se advirtiera un aumento de éstos en términos cuantitativos, pero no así en términos de cobertura.

${ }^{17}$ La última consulta realizada corresponde con los datos ofrecidos por el MEYSS en mayo de 2014.

${ }^{18}$ Se insiste en que los datos de 2013 deben leerse con total cautela pues el registro de convenios por parte del Ministerio de Empleo se ha venido realizando con un retraso considerable, especialmente durante los dos últimos años. 


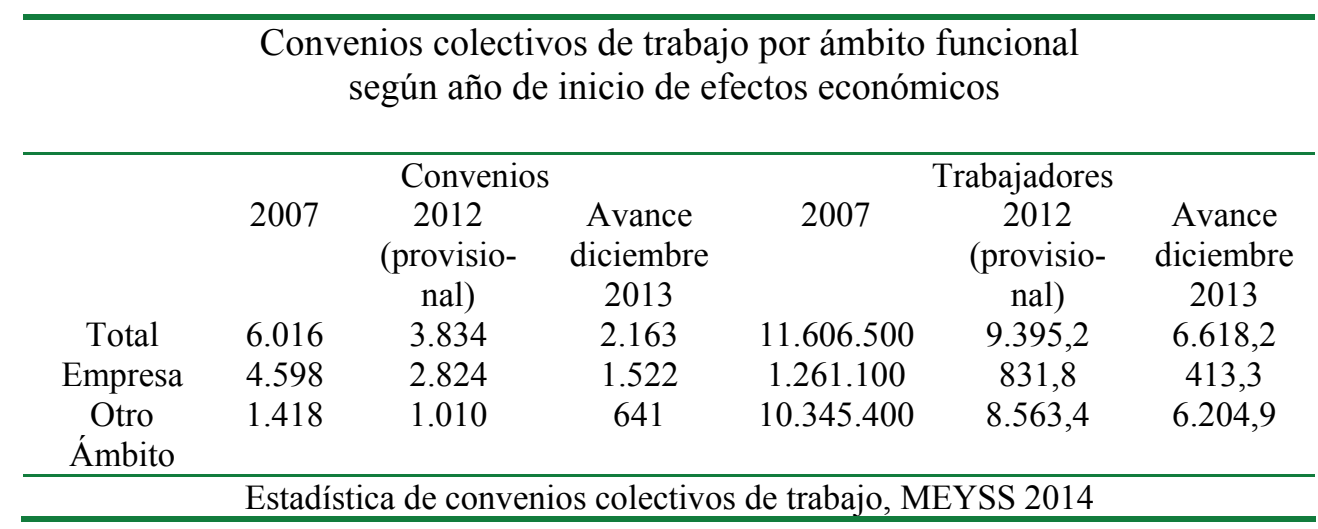

En el trasfondo de esta parálisis se encuentra la profunda rebaja salarial y la devaluación interna que se ha producido en cinco años de esta intensísima crisis económica, pero sin duda también se encuentra vinculada al instrumento que permite la limitación de la ultra-actividad de los convenios. En efecto, la prórroga forzosa de los convenios colectivos garantizaba que la tasa de cobertura de nuestra negociación fuera muy alta (Alonso Mellado, 2012), concediendo a los trabajadores una cierta posición de fuerza a partir de la cual podían mitigar o incluso bloquear las pretensiones regresivas en la fase de renovación de los convenios, sobre todo si apreciaban que no estaba justificada tal regresión en el nivel garantizado por el convenio prorrogado. La información disponible y los datos existentes en 2012 y las previsiones para 2013 parecen indicar que el diagnóstico sobre la evolución en el futuro próximo indica que será más negativo que los datos de los años anteriores (Pérez Infante, 2012). Según la información de la mencionada Estadística de Convenios, la tendencia hacia la inaplicación de los convenios es creciente en los primeros 10 meses del año 2013, que alcanzan a casi 160.00 trabajadores. Las variadas fórmulas para la inaplicación del convenio muestran ${ }^{19}$ las extraordinarias facilidades con que cuenta el empresario para hacerlo. La mayoría de las inaplicaciones son de carácter salarial sobre condiciones pactadas en los convenios de ámbito superior, y afectando especialmente a empresas que se encuadran en el sector servicios y de tamaño pequeño (hasta 50 trabajadores), donde mayor es el poder empresarial.

Desde su dimensión de actores sociopolíticos estables que garantizan la eficacia de la negociación colectiva, las organizaciones sindicales se enfrentan al problema

${ }^{19}$ El propio artículo 82.3 del ET dispone que concurriendo causas económicas, técnicas, organizativas o de producción, por acuerdo entre el empresario y los representantes de los trabajadores, se podrá proceder a inaplicar las condiciones de trabajo previstas en el convenio. El mecanismo de inaplicación tiene una clara vocación temporal, hasta que sea sustituido por un nuevo convenio. 
de que la tasa de cobertura formal de un convenio no implica necesariamente que, en cualquiera de los aspectos pactados a nivel superior al de empresa, la aplicación de lo pactado sea real (y ni siquiera en esta escala de la negociación en la empresa está garantizada su aplicación plena), sino que su materialización y su 'práctica', si bien se hallan estrechamente vinculadas a la situación y posición de la empresa en el mercado productivo y al modo de institucionalización de la negociación colectiva, también se encuentran notablemente relacionadas con el grado de presencia, la implicación y la fuerza de la acción de los sindicatos en los lugares de trabajo (García Calavia, 2007). Como resultado de diversos problemas con las fuentes de datos y a la falta de vocación para abordarlo por parte de los estudios de casos (Pérez Infante, 2011), sobre estos aspectos nucleares de las relaciones laborales existe una tradicional falta de información acerca del grado de incidencia 'real' de la negociación colectiva.

Desde una mirada realista sobre un posible escenario futuro sobre el grado de aplicación efectiva de los convenios, no resulta exagerado aventurar que, junto al amplio (pero decreciente) segmento de la población asalariada que se encuentra formalmente cubierta por la regulación convencional (presidido por los asalariados del sector público), va creciendo el porcentaje de trabajadores asalariados, que bien por razones de falta de representatividad (pequeñas y pequeñísimas empresas donde no se reconoce legalmente el derecho a tener delegado sindical ${ }^{20}$ ), o bien por los profundos efectos de la crisis y la intensa desregulación normativa, se están quedando al margen (en el sentido de marginados) de la regulación convencional -o directamente fuera de su aplicación-. Esto supone una mayor polarización y segmentación, junto a un progresivo incremento de la precarización de las condiciones de trabajo y de vida (Alonso, L. E y Fernández C. 2013). En este complejo contexto de incertidumbre, turbulencia económica e inseguridad laboral no resulta difícil imaginar que las nuevas y diversas formas de dualidad y desigualdad se están multiplicando, que se traducirán en más trabajadores sujetos a una mayor precariedad en sus relaciones laborales, extremadamente flexibles y sin red de seguridad ${ }^{21}$. Este tipo de desestructuración -pues así debería denominarse esta descentralización sin control- no parece recomendable desde la composición del tejido productivo (cuya estructura se asienta en la citada cantidad de pequeñas y medianas empresas), tampoco es oportuna desde el punto de vista de la tutela del trabajo (por la inexistencia de representación de los trabajadores en algunos

${ }^{20}$ Debe anotarse, también, que con datos del año 2012, 1,8 millones de trabajadores $(15,2 \%$ del total de los asalariados), una cantidad que es sustancial, no tienen ningún derecho a representación.

${ }^{21}$ Una síntesis sobre los efectos de la inseguridad y la precariedad laboral se encuentra en el Documento de Trabajo de la OIT (2011) 'Políticas y regulaciones para luchar contra el trabajo precario'. 
ámbitos) y, finalmente, no está demostrado que sea más racional y de mejores resultados que el modelo centralizado y ordenado (Navarro, F., 2009).

\section{Efecto 2: Reducción salarial y empobrecimiento de los trabajadores}

Como los sucesivos Acuerdos Interconfederales han promocionado y recomendado la moderación salarial, en absoluto puede ser considerada como un elemento nuevo (Pérez Infante, 2013). A pesar de ello, las instituciones europeas han recrudecido la presión sobre los salarios, de forma que además de los diversos tipos de modificaciones en materia fiscal e impositiva, aparecen diferentes vías, todas ellas muy activas, para la devaluación de las rentas salariales. Entre estas fórmulas sobresalen, como ya se ha comentado, que las condiciones bajo las que se permite al empresario la reducción unilateral de los salarios no son demasiado estrictas $^{22}$. También se facilita la inaplicación de cláusulas nucleares del convenio colectivo, entre la que se encuentra la posibilidad de que en el convenios de empresa se establezcan salarios inferiores a los fijados en los convenios sectoriales. Los primeros resultados de estas fórmulas no se han hecho esperar y, a pesar de las numerosas dificultades para la cuantificación de la evolución salarial, la generalidad de fuentes estadísticas consultadas confirman que el método adoptado es enormemente eficaz pues el deterioro de la relación salarial se ha producido con gran celeridad y rapidez: España es el país de Europa donde más han bajado los costes salariales $^{23}$, que iniciaron una senda descendente en mayo del 2010 (OCDE). Así lo demuestra la evolución reciente de los salarios brutos ${ }^{24}$, que registra una reducción interanual del $0,8 \%$ en el tercer trimestre de 2013. Si se aplica la influencia de los precios (IPC-medio), el incremento de los salarios brutos reales reflejaría una caída del $2,5 \%{ }^{25}$.

${ }^{22}$ Establece la presunción de que concurren causas cuando de los resultados de la empresa se desprenda una situación económica negativa, como la existencia de pérdidas actuales o previstas, o la disminución persistente de su nivel de ingresos o ventas. En todo caso, se entenderá que la disminución es persistente si se produce durante dos trimestres consecutivos.

${ }^{23} \mathrm{El}$ coste salarial incluye salario base, complementos salariales, pagos por horas extraordinarias, pagos extraordinarios y pagos atrasados, medidos en términos brutos. El coste salarial disminuyó en el segundo trimestre de 2013 un $0,6 \%$ en tasa interanual, pasando de $1.939,73$ a $1.928,72$ euros por trabajador y mes, de acuerdo con los datos del INE.

${ }^{24}$ Se equipara el salario bruto con el coste salarial total procedente de la Encuesta Trimestral de Coste Laboral.

${ }^{25}$ No se ha incluido la congelación de los 2,8 millones de empleados públicos. 
Salarios brutos nominales y reales 2010-2013

(var. interanual; segundos trimestres)

\begin{tabular}{lcccc}
\hline & 2010 & 2011 & 2012 & 2013 \\
Salarios brutos nominales & 1,4 & 0,7 & 0,3 & $-0,8$ \\
IPC & 1,6 & 3,5 & 2,0 & 1,7 \\
Salarios brutos reales & $-0,2$ & $-2,8$ & $-1,7$ & $-2,5$
\end{tabular}

Fuente: elaboración F1 Mayo a partir de la Encuesta Trimestral de Coste Laboral e IPC, INE.

Los datos que aporta Eurostat muestran que los costes laborales han caído desde 2010, cuando descendieron un 1,8\% en el conjunto del ejercicio. En 2011 el retroceso fue del $1 \%$ y el golpe más fuerte se produjo el año pasado, cuando el indicador se hundió un 2,9\%. Para 2013, el organismo prevé otra caída del 1,9\% (en la zona euro a priori se estabilizarán), que se moderará levemente en 2014: $-1,7 \%$. De acuerdo con las cifras de la Contabilidad Nacional, las remuneraciones salariales disminuyeron un $0,3 \%$ el año pasado. Al excluir los sectores agrícolas y Administración Pública se observa que durante el año 2012 hubo crecimiento salarial (del 1\%), pero ya en 2013 la variación es negativa (del 1\%).

La Estadística de Convenios probablemente sea la más incompleta y parcial de todas las fuentes de la que se puede obtener información sobre salarios ya que el bajo número de revisiones anuales registradas en convenios plurianuales impide conocer los resultados reales en cuanto al número de convenios, empresas y trabajadores, la variación salarial y la jornada media pactada, lo que hay que tener en cuenta a la hora de valorar los datos de la estadística sobre efectos económicos de los convenios registrados ${ }^{26}$. A pesar de ello, los datos disponibles a partir de 2010 coinciden y cofirman lo mismo que se obtiene de otras fuentes sobre la disminución de la evolución de los salarios reales en 0,8 puntos (Pérez Infante, 2013), que se mantiene prácticamente constante en 2011, para reducirse de forma acusada, en 1,3 puntos, en 2012. Esta misma fuente certifica que la disminución de los salarios en el periodo 2008-2012 en el ámbito de empresa han sido de un -1.33\% frente al $-0.88 \%$ de ámbito superior.

El incremento medio inicialmente pactado para 2013, según datos de la Estadística de Convenios colectivos se sitúa en el mes de diciembre en el 0,6\% a nivel general; $0,4 \%$ en los convenios de empresa y $0,6 \%$ en los convenios de otro

26 CCOO (2013) 'Evolución de la negociación colectiva'. http://www.ccoo.es/comunes/recursos/1/doc177481_Informe_Balance_de_la_negociación_ colectiva_2012.pdf 
ámbito $^{27}$. En ese cálculo no se incluye el impacto que tienen los más de 2.500 incumplimientos de convenios, que en todos los casos afecta a la cuantía salarial, sobre casi 160.000 trabajadores. Además, está calculado sobre los poco más de 5 millones de asalariados que tenían un convenio en vigor en diciembre de 2013, no sobre los más 12 millones de afiliados a la Seguridad Social, por lo que se constata un descenso muy importante del incremento salarial medio pactado en años precedentes y en relación al mismo periodo del año anterior cuando el incremento registrado alcanzó el $1,24 \%{ }^{28}$, poniendo en evidencia una fuerte caída de los salarios, que se suma a las registradas en años anteriores ${ }^{29}$.

De lo que no parece haber duda es de que la exclusión económica de una parte importante de la población que carece de un empleo retribuido dignamente origina un escenario en que destaca la aparición de un nuevo estrato social: la de quienes, aún trabajando, manifiestan dificultades para salir del riesgo de la pobreza. Son los denominados 'trabajadores pobres' ${ }^{30}$, que tienen empleo, pero cuyos ingresos como fruto del mismo resultan inferiores al mínimo necesario para atender sus necesidades materiales. Su crecimiento exponencial en nuestro país se encuentra en relación directa con la importante reducción de renta de la población asalariada en PIB (que ha descendido un 5\% en el segundo trimestre de 2013, sumado a las sucesivas reducciones registradas durante los dos años anteriores) ${ }^{31}$. En relación al círculo de la pobreza habría que añadir que en el año 2012, 12,7 millones de personas en España se encuentran en situación de riesgo de pobreza o exclusión social, lo que representa un $27 \%$ de la población, es decir, casi una de cada tres personas se encuentra en esta situación. En términos absolutos, si contabilizamos desde el año 2008, encontramos que 2,1 millones de personas han pasado a situarse por debajo del umbral de pobreza en España (con ingresos inferiores al 60\% de los ingresos medianos). En el mismo sentido conviene también subrayar que 3 millones de personas se encuentran en una situación de pobreza severa (con ingresos inferiores al $40 \%$ de los ingresos medianos), lo que supone un $6,4 \%$ de la población,

\footnotetext{
${ }^{27}$ Última consulta a la basa de datos de Convenios Colectivos del MEYSS en mayo 2014.

CCOO (2013). Evolución de la negociación colectiva. http://www.ccoo.es/comunes/recursos/1/ doc177481_Informe_Balance_de_la_negociacion_colectiva_2012.pdf.

${ }^{29}$ Rocha, et al (2013): Crisis, políticas de austeridad y trabajo decente. Estudios de la Fundación $\mathrm{n}^{\circ} 71$. Fundación $1^{\circ}$ de Mayo.

${ }^{30}$ VVAA. (2012) 'Trabajadores pobres y empobrecimiento en España'. Fundación $1^{\circ}$ de Mayo.

${ }^{31}$ Un informe a partir de datos del INE elaborado por Fedea (2013) confirma que comparando tramos salariales, los salarios de los trabajadores del tramo más bajo se han hundido un $17 \%$ entre 2008 y 2012.
} 
y duplica el número de personas que se encuentran atrapados en esta situación en relación a los datos de $2008^{32}$.

\section{Efecto 3: Declive de la 'gobernanza' interna}

Un tercer efecto destacable de esta profunda transformación es su carácter político, pues erosiona gravemente los sistemas de representación de intereses entre patronal y organizaciones sindicales (Luque Balbona, 2012), rompiendo la interacción estratégica y el consenso básico entre ellos. Se pone por tanto de manifiesto que los resultados de las negociaciones colectivas pueden ser sustancialmente diferentes en función del diseño institucional y organizativo de las instituciones del mercado de trabajo, en el sentido de que la política en materia de negociación colectiva en un determinado contexto puede ser radicalmente distinta en otro, siendo asimismo perfectamente posible que los negociadores busquen una relación convergente de los mercados de trabajo con el marco institucional de las relaciones de trabajo o busquen conscientemente la divergencia (González, J. y Vacas, C, 2007). Así como las reglas definen la negociación como un mecanismo de traducción de la correlación de fuerzas y las relaciones de poder entre los agentes sociales, la concepción de la negociación como una vía de equiparación o equilibrio de poderes requiere, como condición básica para que funcione mínimamente como tal, que ésta provoque simultáneamente una restricción a las potestades unilaterales del capital y una aceptación del diálogo por parte de los representantes de los trabajadores, y esto es precisamente lo que se pone en cuestión (García Calavia, 2006).

En dirección totalmente opuesta, el abandono del ámbito clásico de la negociación 'institucionalizada' se orienta a robustecer el poder de dirección, al tiempo que disminuye la capacidad de los trabajadores y sus organizaciones y se limita el alcance de la negociación colectiva (Escudero, R. 2012), en definitiva, se deshumanizan las relaciones de trabajo. El giro de 180 grados del modelo que evoluciona para erosionar el protagonismo evidente de las organizaciones sindicales, convirtiendo a los sindicatos en unos actores más entre múltiples actores posibles, es una distorsión de las reglas de juego que no puede esconder su marcado carácter político. El contexto de debilitamiento y la pérdida de legitimidad del actor sindical en la escena de la negociación se deriva de la posible unilateralidad del empresario en la actuación y las medidas a adoptar en el caso de que su empresa tenga problemas, sin que medie ningún control respecto a la proporcionalidad o idoneidad de las mismas, configurando una grosera (por evidente) relación de dominio entre empleadores y empleados.

${ }^{32}$ Cruces, J. y Fuente, L. (2013). 'Más pobres y con menos derechos: un diagnóstico de la pobreza en España’. Fundación 1 de Mayo. 
Aún teniendo en cuenta que el contexto económico actual favorece las estrategias empresariales -por el cinturón que el alto desempleo supone para las demandas sindicales-, la norma consagra y consolida la erosión del equilibro de poderes entre las partes y desestabiliza las reglas de la gobernanza de la negociación y sus productos. Este proceso de debilitamiento e invisibilización de los sindicatos también se deriva la posibilidad de que la negociación con el empresario se pueda implementar por organismos 'asindicales' o no sindicales. De hecho, en el procedimiento de negociación de instituciones tan relevantes como la modificación sustancial de condiciones colectivas de trabajo o la suspensión o extinción del contrato de trabajo, se puede derivar en la actualidad a la figura del acuerdo de empresa, que podría ser suscrito, ya desde la reforma laboral del año 2010, por una comisión formada por tres trabajadores en el caso de falta de representación sindical (Mejías, A., 2013). A ello habría que añadir que la elevadísima proporción de pequeñas empresas, de facto, imposibilita el mantenimiento de un sistema exhaustivo de negociación, pues no existen recursos disponibles para negociar en una multitud de microempresas.

La ruptura del concepto de interdependencia -que implica la aceptación de que ninguna de las partes puede por sí sola resolver los problemas planteados y que la negociación no sería necesaria en el caso de que una parte tuviera la fuerza para imponer condiciones a la otra- revela que la fuerza de los convenios colectivos reside en la capacidad de los firmantes de obligar a las demás partes a respetar sus compromisos, que cuanto más claros sean, más fuerza ejecutoria tendrán los acuerdos. Lo que se rompe es la idea de cooperación y 'gobernanza' compartida, mediante la cual se reconoce a los empresarios potestades específicas en el ejercicio del poder dentro de la empresa, pero que al mismo tiempo confiere derechos a los trabajadores que operan como límites a esas facultades de dirección y organización.

Por el lado de los intereses empresariales, el asunto tampoco está del todo claro. El modelo 'low cost' con base en la alta flexibilidad productiva (López Acosta 2013) asociado con un tipo de empresario cortoplacista y con escasa visión de futuro, daría como resultado un modelo de escasa proyección y falta de sostenibilidad, vinculada a la utilización del factor trabajo a menor precio y a una espiral sin fin de precariedad que acaba afectando a toda la sociedad. El precio de romper parcial o totalmente las relaciones de trabajo, en definitiva, puede suponer enormes riesgos y un precio muy alto.

Otro modelo de competitividad y recomposición productiva de carácter más estructural y con mayor recorrido sería posible si se priorizara la capacidad de la empresa para ofrecer bienes o servicios con mayor valor añadido, de conseguir una mayor calidad, con procesos y productos más innovados tecnológicamente y con mejor precio comparativo, obtenidos por incrementos de la productividad y modernización de los procesos de producción y organizativos, y perdurable en el tiempo. Este modelo requiere de la incentivación de una mayor participación de los trabajadores y sus representantes en la gestión, desde la convicción de que la empresa es también algo suyo, es decir, un modelo con más y no menos capacidad sindical. 


\section{Valoración final}

La negociación colectiva entendida como uno de los derechos fundamentales, ligada a la libertad sindical y trabajosamente conseguida por el movimiento obrero, introducía distintos mecanismos de equilibrio en la fijación de las condiciones de trabajo en la relación entre empleador y empleado, a través de una función de protección del trabajador. El objetivo de tratar de adaptar nuestro marco contractual laboral a las nuevas realidades productivas se ha realizado desde una visión oportunista, donde el retroceso de los sistemas de negociación colectiva ha dado un salto hacia un modelo singular en el ámbito de la Unión Europea, en el que el marco sectorial ha perdido terreno y las relaciones laborales han perdido democracia.

Sin embargo, en un entorno altamente globalizado, donde la competencia entre las empresas es y será cada vez mayor, su alcance debería entenderse desde la perspectiva de la capacidad para activar y desarrollar la actividad económica, la innovación tecnológica, de mejorar de la productividad, de su capacidad para priorizar y apostar por la innovación y la creación de procesos productivos con alto valor añadido. Pero también por su capacidad para construir y afianzar identidades profesionales sectoriales, de crear marcos de diálogo entre actores múltiples y diversos y, sobre todo, como espacio de construcción de relaciones sociales más equitativas y más justas entre las personas que participan en el mundo del trabajo, y eso solo se consigue con empresas que funcionen con base en relaciones laborales regidas por el acuerdo y el diálogo.

Parece inevitable que los nuevos convenios que se acuerden y pacten a partir de ahora sean muchos menos y de menor calidad, pero a esta disminución habría que añadir la posibilidad de que esta pérdida de calidad, tenga además como resultado el vaciamiento de sus contenidos. Si la apuesta estratégica por la eliminación de los marcos generales de negociación no resulta eficaz ni siquiera para los intereses económicos en el medio plazo de las estructuras productivas, y tampoco sirve como escenario para la representación de los diversos y legítimos intereses, el análisis clásico sobre el objetivo real de esta acción se preguntaría sobre quién resulta beneficiado por ella. En el caso de que se trate de encapsular la negociación a nivel de la empresa para imponer la competencia destructiva de costes laborales y el recorte de derechos, impulsando una función de la negociación que no afecte o altere la tasa de ganancia, el objetivo podría ser que los sindicatos, si no desaparecen, resulten superfluos. Pero en la medida en que la cuestión de la protección de los derechos y de intereses legítimos queda en entredicho, parece obviarse que los perjudicados no sólo son los trabajadores, sino también las empresas y, desde luego, el conjunto del sistema productivo de nuestro país, lo que supone un alto precio. 


\section{Bibliografía}

Alonso Mellado, C. (2012). Un intento de acabar con la negociación colectiva. I Congreso 'Economía, trabajo y sociedad'. Fundación 1 de Mayo.

Alonso, L. E. (2011). Gobierno o gestión? El Estado remercantilizador y la crisis de lo social. Revista Encrucijadas Núm. 1.

Alonso, L. E. y Fernández, C. (2013). Los discursos del presente. Siglo XXI.

Bauman, Z. (2002). Modernidad líquida. Fondo de Cultura Económica de España.

Bentolilla, S. y Jimeno, J.F. (2002). La reforma de la negociación colectiva en España, Documentos de trabajo FEDEA.

Clauwaert and Schomann (2012). The crisis and national labour law reforms: a mapping exercise. ETUI.

Confederación Europea de Sindicatos (2012). Solidaridad en la crisis y más allá: hacia un enfoque sindical europeo coordinado contra el dumping social.

Comisión europea (2012). Relaciones Industriales en Europa. Dirección General de Empleo, Asuntos Sociales e Inclusión.

Escudero, R. (2013). La aplicación de la reforma laboral de 2012 o el anunciado réquiem por la Flexiseguridad' Revista de Relaciones Laborales.

- (2013). La negociación colectiva en las reformas laborales de 201, 2011 y 2012. Ed. Cinca.

Fernández, M. F. (2013). Libertad sindical y medios de acción: reformas esperadas tras las reformas legales. Representación y libertad sindical: la LOLS y la Sección Sindical en la pequeña y mediana empresa. UGT.

García Calavia, M.A. (2006). Sindicatos y representación de intereses. Revista Mientras Tanto Núm. 99.

- (2007). La estructura de la negociación colectiva. http://www.fesweb.org/uploads /files/modules/congress /10/ grupos trabajo/ponencias/577.pdf.

García Serrano, C. (2011). Déjà vu? Crisis de empleo y reformas laborales en España .Revista de Economía Aplicada, 56 pp. 149-177.

Gómez Acosta, M. (2013). La industria como modelo productivo. Blog Metiendo bulla. 
González de Lena, F. (2013). Economía y Trabajo. Blog Fabianoshoy.org.

González Mínguez J. y Vacas, C. (2007). La flexiguridad como modelo para los mercados de trabajo europeos Servicio de Estudios del Banco de España.

Lahera, J. (2013). Equilibro en los convenios. Diario El País, 4 de noviembre de 2013.

Laparra, M. y Pérez E. (2012). Crisis y fractura social en Europa. Obra Social 'La Caixa'.

Luque Balbona, D. (2012). Huelgas e intercambio político en España. Revista Internacional de Sociología.

Merino, A. (2012). La negociación colectiva después de la reforma laboral de 2012. Bomarzo.

Mejías, A. (2013). La sección sindical y la acción sindical en la pequeña y mediana empresa. Representación y libertad sindical: la LOLS y la Sección Sindical en la pequeña y mediana empresa. UGT

Navarro, F. (2009). La estructura de la negociación colectiva. Bomarzo.

OCDE (2013). The 2012 labour market reform in Spain: a preliminary assessment.

Pérez de Guzmán, S. (2012). Negociación colectiva, acción sindical e intercambio político. Un planteamiento teórico apoyado en el análisis de las relaciones laborales en los astilleros de Cádiz. Papers.

Pérez L. y Viñas A. I. (2013). A más austeridad, más depresión. Anuario de relaciones laborales en España. UGT.

Pérez de los Cobos y F. Thibault J. (2010). La reforma de la negociación colectiva (1) Relaciones Laborales, Núm. 14.

Pérez Infante, J. I. (2013). Los salarios se desmoronan. Asociación española de economistas del trabajo.

- (2011). 'La negociación colectiva y los salarios'. Cuadernos de Relaciones Laborales Núm. 29.

- (2013). 'Crisis, reformas laborales y devaluación salarial'. X Jornadas de Economía Laboral. 
Rodríguez, L. (2012). Menos negociación colectiva, menos igualdad y menos democracia. Economistas contra la crisis.

- (2014). "Imperativos económicos frente a derechos fundamentales, un nuevo paradigma de relaciones laborales", en Revista de Derecho Social, Núm. 65, págs. 41-68.

Rojo, E. (2013) La (s) reforma (s) laboral (es) de 2012 y 2013. Objetivos declarados. ¿Objetivos ocultos?. Curso de verano sobre la reforma laboral. Universidad Rey Juan Carlos.

Sanguinetti, W. (2012). La Ley 3/2012: un paso más en el desequilibrio del sistema de negociación colectiva. Blog del autor.

Sennet, R. (2000). La corrosión del carácter. Anagrama. 